\title{
Microstructural, mechanical, and corrosion characterization of plasma-nitrided plastic injection mould steel
}

\author{
Orhan Öztürk $^{\mathrm{a}, *}$, Ortaç Onmuşs ${ }^{\mathrm{a}}$, D.L. Williamson ${ }^{\mathrm{b}}$ \\ ${ }^{a}$ Department of Physics, Izmir Institute of Technology, Izmir 35430, Turkey \\ bhysics Department, Colorado School of Mines, Golden, CO 80401, USA
}

Available online 27 September 2004

\begin{abstract}
Plasma nitriding can be used to improve wear and corrosion behaviour of moulds for plastic injection by modifying the near-surface layers of these materials. In this study, a ferritic stainless steel (X36CrMo17) was plasma nitrided at $520-540{ }^{\circ} \mathrm{C}$ for $15-18 \mathrm{~h}$ under various gas mixtures of $\mathrm{N}_{2}+\mathrm{H}_{2}$ in an industrial nitriding facility. The nitrided layer microstructures, thicknesses, and strengths were studied by X-ray diffraction (XRD), conversion electron and X-ray Mössbauer spectroscopies (CEMS and CXMS), cross-sectional scanning electron microscopy (SEM), and cross-sectional nanohardness measurements. The corrosion behaviour was investigated by a salt spray method. Combined Mössbauer, XRD, and SEM analyses demonstrate that ( $\mathrm{Fe}, \mathrm{Cr}, \mathrm{Mn}$ )-nitrides, the $\varepsilon$ - and $\gamma^{\prime}$-nitrides, the $\mathrm{Fe}_{3} \mathrm{C}$-like carbide, and $\mathrm{CrN}$ are distributed in the top nitrided layers of several micron thickness. The CEMS and CXMS analyses clearly show the nearly complete decomposition of the surface and deeper layers into phase separated mixtures of pure bcc-Fe, (Fe, $\mathrm{Cr}, \mathrm{Mn})$-nitrides, and CrN. The nitriding conditions with the gas composition $\mathrm{N}_{2} / \mathrm{H}_{2}=1$ produces the thickest nitrided layer $(\sim 135 \mu \mathrm{m})$ with enhanced corrosion protection. The nanohardness of the surface layers is found to be plateau-shaped and increased by about a factor of three in comparison to that of the substrate material.
\end{abstract}

(C) 2004 Elsevier B.V. All rights reserved.

Keywords: Plasma nitriding; Injection mould steel; X-ray diffraction; Mössbauer spectroscopy; Nanohardness; Salt spray corrosion analysis

\section{Introduction}

$\mathrm{X} 36 \mathrm{CrMo} 17$ (similar to AISI-420F) is a tool steel widely used in the plastics moulding industry. Moulds for plastic injection are normally high-cost and quite complicated, consisting of many parts in relative motion with respect to each other and to the plastics material, leading to tribological problems in the moulds. Heating during injection moulding causes plastic materials to liberate gases resulting in local corrosion and wear of the mould material. In addition, abrasion, adhesion, sticking, and fatigue are the most commonly occurring problems associated with these materials $[1,2]$. Tribological problems in connection with the moulding of plastics can often be solved by an appropriate surface modification technique. Plasma ion

\footnotetext{
* Corresponding author. Tel.: +90 232750 7513; fax: +90 232750 7509.

E-mail address: orhanozturk@iyte.edu.tr (O. Öztürk).
}

nitriding, a well-established commercial surface hardening process, can be used to improve wear and corrosion behaviour of moulds for plastic injection. In this process, by means of a glow discharge in a gas of $\mathrm{N}_{2}$ and $\mathrm{H}_{2}$, with the steel (the cathode) at a temperature of the order of magnitude $500{ }^{\circ} \mathrm{C}$, nitrogen can penetrate the surface and diffuse into the steel [3]. Under such conditions, the structure of the nitrided layers is such that the top nitrided layer, known as the compound layer, is composed mainly of $\gamma^{\prime}-\mathrm{Fe}_{4} \mathrm{~N}$ and $\varepsilon-\mathrm{Fe}_{2-3} \mathrm{~N}$ as well as nitrides with alloying elements. The layer beneath the compound layer is known as the so-called diffusion layer which consists mainly of interstitial atoms in solid solution and fine, coherent nitride precipitates when the solubility limit is reached. The thicknesses and compositions of these layers vary depending on the process parameters and steel compositions. It is known that the compound layers with iron nitrides have good corrosion resistances. This is found to be the case for the plasma nitriding study of a X20Cr13 ferritic stainless 
steel material (similar to the one investigated in this study) which showed that the plasma nitrided layer with monophase, $\varepsilon-\mathrm{Fe}_{3} \mathrm{~N}$ ( $\varepsilon$-nitride phase) has a good corrosion resistance, as investigated by the ferri/ferrocyanide test [4]. In another investigation [5], a ferritic $\mathrm{X} 6 \mathrm{Cr} 17$ was plasma nitrided between 250 and $500{ }^{\circ} \mathrm{C}$ for $8-60 \mathrm{~h}$ at 300 $\mathrm{Pa}$ and $400-450 \mathrm{~V}$. In contrast to other investigations, gas mixtures included argon in addition to nitrogen and hydrogen $\left(40-80 \% \mathrm{~N}_{2}, 10-30 \% \mathrm{H}_{2}\right.$, and $\left.10-30 \% \mathrm{Ar}\right)$. This study found that the microhardness of the ferritic steel increased with the nitrided layer thickness, while the gas composition had no significant influence on nitriding based on the nitrogen concentration profiles obtained via glow discharge optical spectroscopy. Furthermore, the X-ray diffraction (XRD) results of this study [5] showed ferrite and $\varepsilon-\mathrm{Fe}_{3} \mathrm{~N}$ after plasma nitriding for $26 \mathrm{~h}$ at $350{ }^{\circ} \mathrm{C}$, while the higher temperature treatment $\left(450{ }^{\circ} \mathrm{C}\right)$ resulted in the microstructures consisting of $\varepsilon-\mathrm{Fe}_{3} \mathrm{~N}, \gamma^{\prime}-\mathrm{Fe}_{4} \mathrm{~N}$, and $\mathrm{CrN}$. The surface hardening mechanism of a martensitic stainless steel with a base chemical composition of $\mathrm{Fe}-0.40 \% \mathrm{C}-13.5 \%$ $\mathrm{Cr}$, also used for moulds for plastic injection, was investigated by plasma nitriding at temperatures ranging from 480 to $560{ }^{\circ} \mathrm{C}$ using a fixed time of $4 \mathrm{~h}$ and a gas mixture ratio of $\mathrm{N}_{2} / \mathrm{H}_{2}=3 / 1$. This study [6] showed that the hardening effect was due to a fine and homogeneous chromium nitride precipitation. The flat type of the hardness profile obtained in this research was attributed to strong interaction characteristics of $\mathrm{Cr}$.

In the present study, we investigate the effectiveness of conventional plasma nitriding conditions in improving the tribological and corrosion properties of $\mathrm{X} 36 \mathrm{CrMo} 17$ injection mould steel. In particular, hardness and corrosion behaviour of the nitrided layers under various $\mathrm{N}_{2}+\mathrm{H}_{2}$ gas compositions are investigated. Our study combines the use of X-ray diffraction (XRD), conversion electron, and X-ray Mössbauer spectroscopies (CEMS and CXMS), cross-sectional scanning electron microscopy (SEM), and crosssectional nanohardness measurements. The corrosion behaviour is investigated by a salt spray method.

\section{Experimental}

Plasma nitriding of ferritic (bcc) $\mathrm{X} 36 \mathrm{CrMo} 17$ stainless steel with a base chemical composition $\mathrm{Fe}-0.33 \% \mathrm{C}-16.7 \%$ $\mathrm{Cr}-1.35 \% \mathrm{Mn}$ (all in wt.\%) was performed in an industrial nitriding facility (micropulsed DC). The specimens had a disc-like geometry with a diameter of $3.0 \mathrm{~cm}$ and a thickness of $0.30 \mathrm{~cm}$. This geometry was specifically designed for friction and wear analysis before and after the plasma nitriding. The wear analysis results will be published separately. Before plasma nitriding and sputter cleaning in hydrogen plasma, all the specimens were polished to a mean surface roughness of about $0.02 \mu \mathrm{m}$ based on surface profilometry. The plasma nitriding experiments were performed in the temperature range of $520-540{ }^{\circ} \mathrm{C}$ for 15 to 18
Table 1

Plasma ion nitriding process conditions

\begin{tabular}{llll}
\hline Specimen no. & $\begin{array}{l}\text { Gas flow } \\
\text { ratio }\left(\mathrm{N}_{2} / \mathrm{H}_{2}\right)\end{array}$ & $\begin{array}{l}\text { Temperature } \\
\left({ }^{\circ} \mathrm{C}\right)\end{array}$ & $\begin{array}{l}\text { Nitriding } \\
\text { time }(\mathrm{h})\end{array}$ \\
\hline $\mathrm{S} 10, \mathrm{~S} 11, \mathrm{~S} 12$ & $1 / 10$ & 520 & 15 \\
$\mathrm{~S} 3, \mathrm{~S} 4, \mathrm{~S} 5, \mathrm{~S} 6$ & $1 / 1$ & 540 & 18 \\
$\mathrm{~S} 13, \mathrm{~S} 14, \mathrm{~S} 15$ & $3 / 1$ & 520 & 15 \\
\hline
\end{tabular}

h. The temperatures of the specimens were measured by chromel-alumel thermocouples attached to the back of the samples. The bias voltage and working pressure during nitriding were $500 \mathrm{~V}$ and 2-3 mbar, respectively. Prior to plasma nitriding, the specimens were subjected to cleaning by hydrogen sputtering for $45 \mathrm{~min}$ under a bias voltage of $520 \mathrm{~V}$ and a temperature of $525{ }^{\circ} \mathrm{C}$. The plasma nitriding conditions for the specimens of this research are summarized in Table 1.

XRD was done in the symmetric $\theta / 2 \theta$ Bragg-Brentano mode using a Philips Expert XRD system in a step-scanning mode $\left(0.05^{\circ}\right.$ step size and $4 \mathrm{~s}$ count-time per step). The CEMS and CXMS techniques provide quantitative Fecontaining phase analysis at much different probe depths ( $\sim .1$ and $\sim 12 \mu \mathrm{m}$, respectively) as described previously [7]. Cross-sectional SEM was done after acid etching in nital and Vilella's reagent solutions for a few seconds. Crosssectional nanohardness profiles were obtained using a CSEM tester equipped with a Vickers indenter. The applied load was $10 \mathrm{mN}\left[1 \mathrm{~g},\left(H_{\mathrm{V}}=0.01\right)\right]$. The corrosion behaviour was investigated by a salt spray method $(2 \% \mathrm{NaCl}$ solution in distilled water) and by observation (via optical microscopy and SEM) of the acid etching effects of SEM sample preparation. The surface roughness of the as-polished and as-nitrided specimens was measured using a Mahr stylus profilometer.

\section{XRD results and discussion}

Fig. 1 shows the XRD results for the nitrided specimens with the gas composition ratios of $\mathrm{N}_{2} / \mathrm{H}_{2}=1 / 10,1 / 1$, and 3/1 corresponding to the nitrided samples S11, S4, and S14 (Table 1). Included in the same figure are the results for the as-polished sample (the substrate material). In Fig. 1, the substrate (X36CrMo17) peaks are labeled as " $\alpha$ " for the bcc $\alpha-(\mathrm{Fe}, \mathrm{Cr}, \mathrm{Mn})$ phase and " $\mathrm{C}$ " for the $\mathrm{CrFe}$-carbide phase $\left(\mathrm{Cr}_{\sim 16} \mathrm{Fe}_{\sim 7} \mathrm{C}_{6}\right)$. The volume percent of this phase is estimated to be about 2 to $3 \mathrm{vol} . \%$ based on the intensity of the XRD peaks. The XRD results for the plasma nitrided specimens with various $\mathrm{N}_{2}+\mathrm{H}_{2}$ gas compositions clearly show the formation of ( $\mathrm{Fe}, \mathrm{Cr}, \mathrm{Mn})$-nitrides (labeled $\varepsilon$ and $\gamma^{\prime}$ ), and $\mathrm{CrN}$ in the top nitrided layers. The $\varepsilon$ and $\gamma^{\prime}$ refer to the hexagonal and ordered fcc nitrides, $\varepsilon-(\mathrm{Fe}, \mathrm{Cr}, \mathrm{Mn})_{3} \mathrm{~N}$ and $\gamma^{\prime}-(\mathrm{Fe}, \mathrm{Cr}, \mathrm{Mn})_{4} \mathrm{~N}$.

While the formation of $\mathrm{CrN}$ is observed for all the nitriding conditions, the $\varepsilon$ - and $\gamma^{\prime}$-nitrides, are only formed for higher gas flow rate samples $\left(\mathrm{N}_{2} / \mathrm{H}_{2}=1 / 1\right.$ and $3 / 1$ 


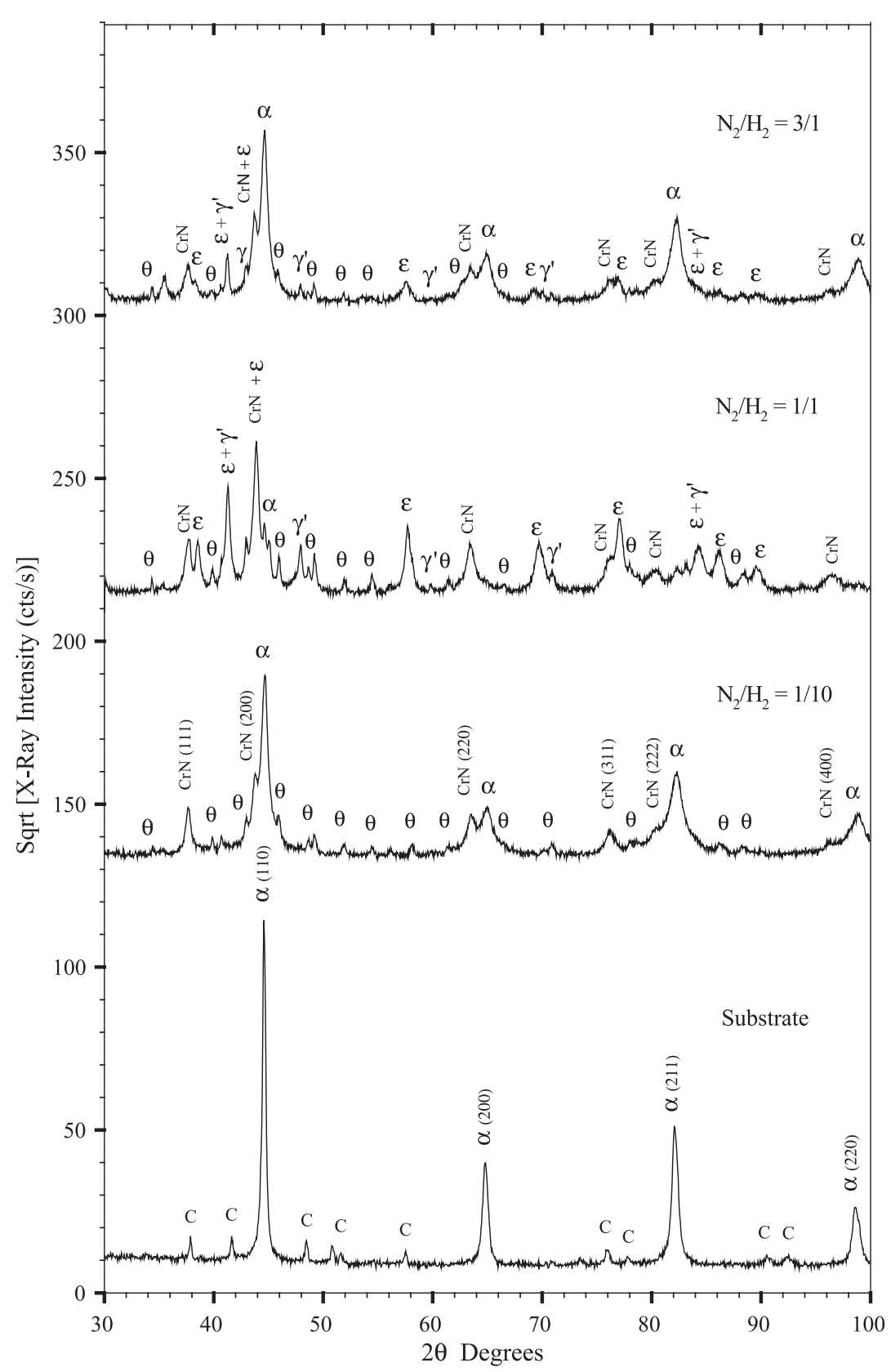

Fig. 1. XRD data for the as-polished sample and after plasma nitriding at the indicated $\mathrm{N}_{2} / \mathrm{H}_{2}$ gas composition ratios. Note that the square root of the intensity is plotted to reveal more clearly the weaker peaks.

specimens, see Table 1). The clear observation of $\mathrm{CrN}$ under the nitriding temperatures of this study $\left(520-540{ }^{\circ} \mathrm{C}\right)$ regardless of the various gas mixtures of $\mathrm{N}_{2}+\mathrm{H}_{2}$ is consistent with earlier studies $[4,8]$, which show that $\mathrm{CrN}$ begins to precipitate when plasma nitriding high-chromium steels at temperatures above $450{ }^{\circ} \mathrm{C}$. In our case, the dissolution of the $\mathrm{Cr}$ results in a phase separated mixture of bcc-Fe(Mn) (note that the substrate peaks are shifted to lower angles) and $\mathrm{CrN}$. As a result of plasma nitriding, the intensities of the substrate XRD peaks are seen to be reduced due to increasing nitrided layer thickness. Semiquantitative and qualitative analyses of the XRD data in Fig. 1 indicate that the $\mathrm{N}_{2} / \mathrm{H}_{2}=1 /$ 1 specimen has much higher amounts of $\varepsilon$ - and $\gamma^{\prime}$-nitrides in the top nitrided layer (compound layer) in comparison to the sample with the $\mathrm{N}_{2} / \mathrm{H}_{2}=3 / 1$ which shows weak XRD peaks for these phases. The lower contents for these phases for the latter $\mathrm{N}$-richer conditions might be due to the intense sputtering taking place during plasma nitriding at high gas composition ratios. The rms roughness for the specimen nitrided under the $\mathrm{N}_{2} / \mathrm{H}_{2}=3 / 1$ plasma processing conditions is $\sim 0.84 \mu \mathrm{m}$ in comparison to those for the $\mathrm{N}_{2} / \mathrm{H}_{2}=1 / 1$ and the as-polished specimens, which are $\sim 0.40$ and $0.02 \mu \mathrm{m}$, respectively. The nitrided layer with a polyphase microstructure containing $\varepsilon$ - and $\gamma^{\prime}$-nitrides was also seen for an AISI 410 steel $(12.5 \mathrm{wt} \% \mathrm{Cr})$ that was plasma nitrided for 4 and $9 \mathrm{~h}$ at $580{ }^{\circ} \mathrm{C}[8]$. 
The XRD data also show the existence of small intensity peaks labeled " $\theta$ " in Fig. 1. These peaks are identified as those of cementite, $\mathrm{Fe}_{3} \mathrm{C}$. There may also be some $\mathrm{Mn}$ and $\mathrm{Cr}$ substitution in this phase (i.e., $\left.(\mathrm{Fe}, \mathrm{Cr}, \mathrm{Mn})_{3} \mathrm{C}\right)$. Both CEMS and CXMS results (to be discussed in the next section) are also consistent with an $\mathrm{Fe}_{3} \mathrm{C}$-like phase. It appears that the $\mathrm{CrFe}$-carbide phase (" $\mathrm{C}$ ") has converted into cementite.

\section{CEMS/CXMS results and discussion}

Figs. 2 and 3 show the CEMS and CXMS results for the as-polished sample and the plasma-nitrided specimens with the $\mathrm{N}_{2}+\mathrm{H}_{2}$ gas composition ratios of $1 / 10$ and $1 / 1$ (samples S11 and S4 in Table 1). Table 2 lists the full quantitative Mössbauer results for all the nitrided as well as the as-
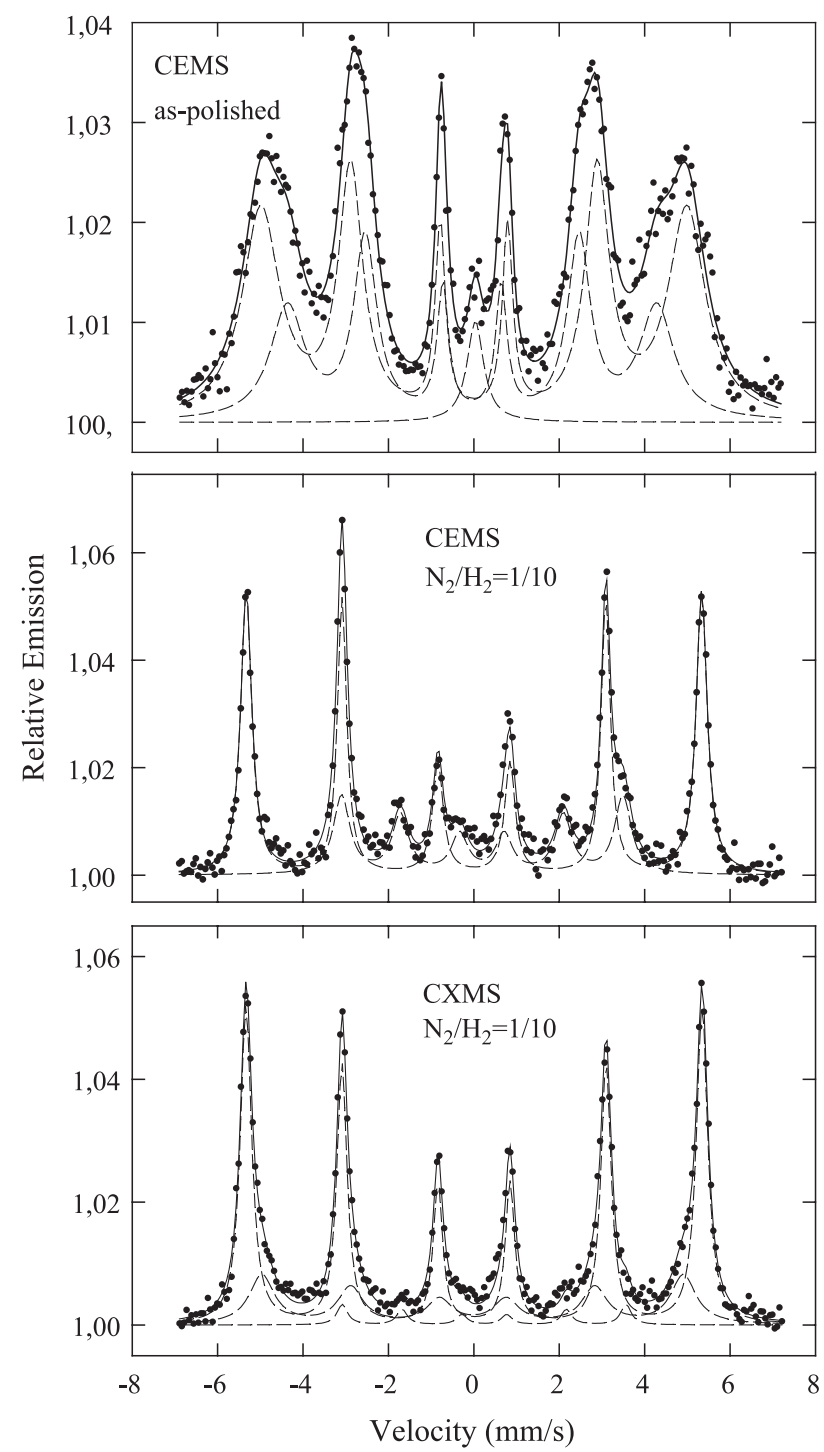

Fig. 2. CEMS and CXMS data for the as-polished sample and the specimen (S11) nitrided under the $\mathrm{N}_{2} / \mathrm{H}_{2}=1 / 10$ plasma nitriding conditions (see Table 2 for full quantitative results).

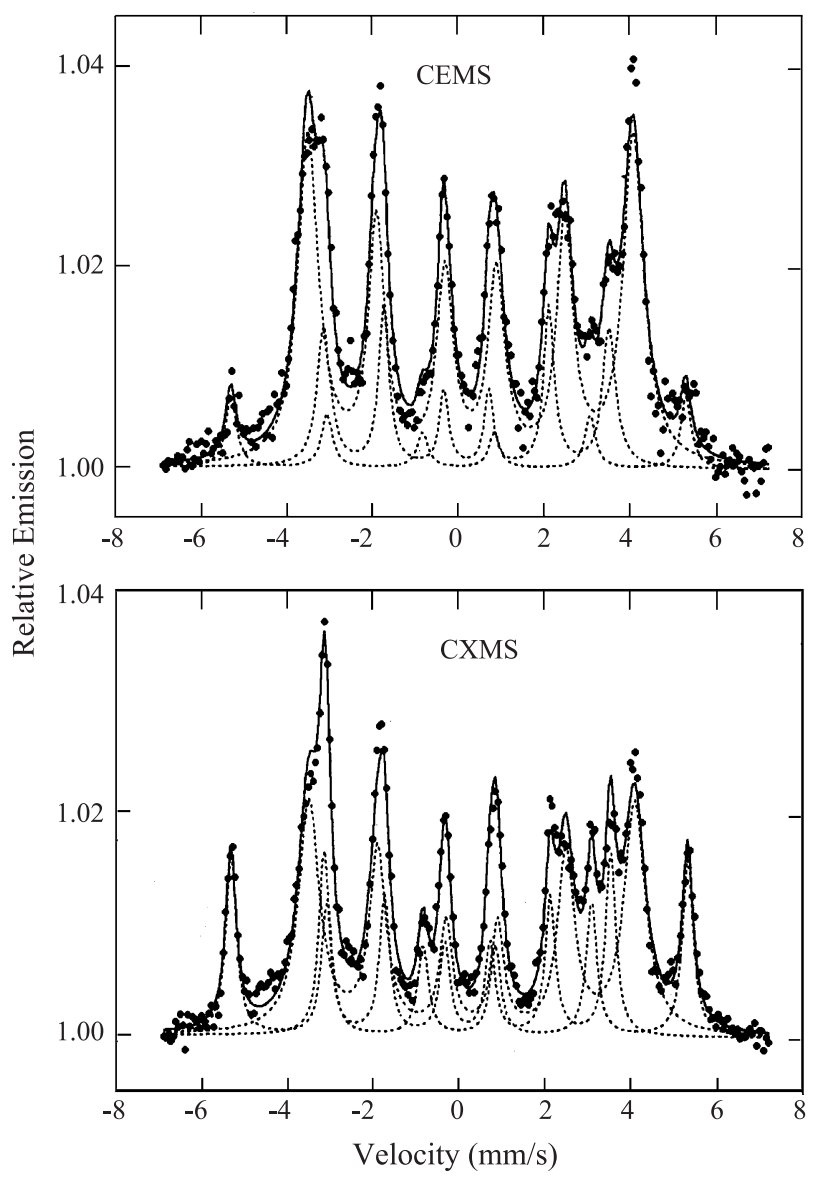

Fig. 3. CEMS and CXMS data for the specimen (S4) plasma nitrided under the $\mathrm{N}_{2} / \mathrm{H}_{2}=1 / 1$ plasma nitriding conditions (see Table 2 for full quantitative results).

polished specimens. The CEMS and CXMS spectra of the as-polished sample are composed of magnetic, bcc $\alpha$ (Fe, $\mathrm{Cr}, \mathrm{Mn})$, and paramagnetic components. The magnetic subspectra are consistent with $\mathrm{Fe}-\mathrm{Cr}$ alloys with a wide range of nearest neighbour environments around the resonant Fe. The small paramagnetic component in Fig. 2 is attributed to $\mathrm{Fe}$ in the $\mathrm{CrFe}$-carbide phase consistent with the XRD results (Fig. 1). The CEMS spectrum of the $\mathrm{N}_{2} /$ $\mathrm{H}_{2}=1 / 10$ specimen shows the nearly complete decomposition of the surface layer into relatively pure bcc Fe $[\alpha-$ $\mathrm{Fe}(\mathrm{Mn})]$ and a magnetic phase whose Mössbauer parameters are quite similar to those of cementite, $\theta-\mathrm{Fe}_{3} \mathrm{C}(H=20.7$ $20.8 \mathrm{~T}$ and $\mathrm{IS}=0.18 \mathrm{~mm} / \mathrm{s}$, Table 2). CXMS, probing much deeper $(\sim 12 \mu \mathrm{m}$ [7]) shows some of the original FeCr alloy (the substrate phase; $H=30.9 \mathrm{~T}$ ); however, this region is also highly decomposed. It is assumed that some $\mathrm{Cr}$ that is depleted from the $\mathrm{FeCr}$ alloy is also forming $\mathrm{CrN}$ based on the XRD results for the specimen nitrided under the $\mathrm{N}_{2}$ / $\mathrm{H}_{2}=1 / 10$ conditions. The large CEMS ( $\left.\mathrm{Fe}, \mathrm{Cr}, \mathrm{Mn}\right)_{3} \mathrm{C}$-like resonance fraction $(30 \%)$ suggests significant carbon segregation to the near-surface region $(\sim 0.1 \mu \mathrm{m})$. This finding raises some important questions regarding the nitriding process and is discussed later. 
Table 2

Mössbauer (CEMS and CXMS) hyperfine parameters and resonance fractions for the as-polished and the specimens nitrided under various gas mixtures of $\mathrm{N}_{2}+\mathrm{H}_{2}$

\begin{tabular}{|c|c|c|c|c|c|c|c|c|c|}
\hline \multirow[t]{2}{*}{$\mathrm{N}_{2} / \mathrm{H}_{2}$} & \multirow[t]{2}{*}{ SS\# } & \multicolumn{4}{|l|}{ CXMS } & \multicolumn{4}{|l|}{ CEMS } \\
\hline & & $\delta$ & $\Delta$ & $H$ & $F$ & $\delta$ & $\Delta$ & $H$ & $F$ \\
\hline \multirow[t]{3}{*}{ As-polished } & SS1 & +00.1 & +0.02 & 31.1 & 59 & +0.01 & +0.02 & 31.0 & 61 \\
\hline & $\mathrm{SS} 2$ & -0.05 & +0.01 & 27.1 & 39 & -0.04 & -0.03 & 26.9 & 36 \\
\hline & SS3 & +0.04 & 0 & 0 & 2 & +0.04 & 0 & 0 & 3 \\
\hline \multirow[t]{3}{*}{$1 / 10$} & SS1 & +0.01 & 0.0 & 33.19 & 66 & +0.01 & 0.0 & 33.13 & 70 \\
\hline & SS2 & -0.03 & +0.04 & 30.0 & 29 & - & - & - & 0 \\
\hline & SS3 & +0.22 & $0.05(\mathrm{f})$ & 20.6 & 5 & +0.19 & +0.05 & 20.5 & 30 \\
\hline \multirow[t]{3}{*}{$1 / 1$} & SS1 & +0.29 & -0.02 & 23.7 & 53 & +0.30 & 0.0 & 23.6 & 69 \\
\hline & SS2 & +0.18 & +0.03 & 20.8 & 23 & +0.19 & +0.03 & 20.7 & 22 \\
\hline & SS3 & +0.01 & $0(\mathrm{f})$ & 33.14 & 24 & $0(\mathrm{f})$ & $0(f)$ & 33.0 & 9 \\
\hline \multirow[t]{3}{*}{$3 / 1$} & SS1 & +0.01 & +0.01 & 33.11 & 79 & +0.01 & $0(f)$ & 33.19 & 35 \\
\hline & SS2 & +0.33 & 0.0 & 23.6 & 21 & +0.34 & 0.00 & 23.62 & 48 \\
\hline & SS3 & - & - & - & 0 & +0.39 & 0.87 & 0 & 17 \\
\hline
\end{tabular}

All measurements were made at room temperature. $\delta$ is isomer shift (relative to $\alpha$-Fe) in $\mathrm{mm} / \mathrm{s}, \Delta$ is quadrupole splitting in $\mathrm{mm} / \mathrm{s}$, and $H$ is the hyperfine field in Tesla. $F$ is the relative resonance area fraction in percent. $\mathrm{f}$ in parentheses indicates that the parameter was fixed and SS\# refers to subspectrum number. The gas composition mixture ratios $\mathrm{N}_{2} / \mathrm{H}_{2}=1 / 10,1 / 1$, and 3/1 associated with the nitrided specimens SC11, SC4, and SC14.

Fig. 3 shows the Mössbauer results for the specimen nitrided under the $\mathrm{N}_{2} / \mathrm{H}_{2}=1 / 1$ conditions having the strongest resonance signals of the three specimens investigated. The CEMS data show two distinct magnetic signals, one of which $(H=20.7 \mathrm{~T}$, see Table 2$)$ is cementite-like $\left[(\mathrm{Fe}, \mathrm{Cr}, \mathrm{Mn})_{3} \mathrm{C}\right]$ and is the same as found for the $\mathrm{N}_{2} / \mathrm{H}_{2}=1 / 10$ sample, and the other is associated with an ( $\mathrm{Fe}, \mathrm{Cr}, \mathrm{Mn})$ nitride whose Mössbauer parameters $(H=23.6-23.7 \mathrm{~T}$, see Table 2) are similar to those of $\varepsilon-\mathrm{Fe}_{3.2} \mathrm{~N}$ [9]. Here, we have $\varepsilon-(\mathrm{Fe}, \mathrm{Cr}, \mathrm{Mn}){ }_{2+{ }_{x}} \mathrm{~N}$ with $x \sim 1$. The CXMS results (Fig. 3) show that a significant amount of the $\varepsilon$-nitride phase is distributed deeper into the nitrided layer (Table 2). The CEMS and CXMS findings of the $\varepsilon$-nitride phase are quite consistent with the strong $\varepsilon$-nitride XRD signals.

The CEMS results (Table 2) for the higher gas flow ratio conditions $\left(\mathrm{N}_{2} / \mathrm{H}_{2}=3 / 1\right)$ show a strong $\varepsilon$-nitride signal near the surface of the nitrided layer. The CXMS results indicate that the nitride signal gets much weaker as one probes deeper into the nitrided layer. However, CXMS results also show a significant amount of decomposition [into pure $\alpha$ $\mathrm{Fe}(\mathrm{Mn})+\mathrm{CrN}+\varepsilon$-nitride] occurring deeper into the substrate. Both CEMS and CXMS findings of the $\varepsilon$-nitride phase agrees quite well with those of the XRD results (the XRD $\varepsilon$ phase peaks for the $\mathrm{N}_{2} / \mathrm{H}_{2}=3 / 1$ sample are much weaker in comparison with those of the $\mathrm{N}_{2} / \mathrm{H}_{2}=1 / 1$ sample). The CEMS results for the $\mathrm{N}_{2} / \mathrm{H}_{2}=3 / 1$ sample, in addition to the magnetic $\varepsilon$-nitride signal, show a paramagnetic component which suggests a higher content $\mathrm{N}$ phase. However, the Mössbauer parameters for this doublet $(\mathrm{QS}=0.87 \mathrm{~mm} / \mathrm{s}$, Table 2) do not match those expected for $\mathrm{Fe}_{2} \mathrm{~N}$ [10]. The CEMS results for the $\mathrm{N}_{2} / \mathrm{H}_{2}=3 / 1$ nitriding conditions show the disappearance of the $\mathrm{Fe}_{3} \mathrm{C}$-like resonance with $H=20.5-$ $20.8 \mathrm{~T}$ (Table 2) that was significantly present for the $\mathrm{N}_{2} /$ $\mathrm{H}_{2}=1 / 10$ and $1 / 1$ samples. Perhaps the cementite-like phase has converted into a paramagnetic carbo-nitride phase as something like $(\mathrm{Fe}, \mathrm{Mn})_{3}(\mathrm{C}, \mathrm{N})$, still having the $\mathrm{Fe}_{3} \mathrm{C}$-like crystal structure, but now with paramagnetic characteristics.
The Mössbauer resonance fractions associated with the $\mathrm{Fe}_{3} \mathrm{C}$-like phase, $\left[(\mathrm{Fe}, \mathrm{Cr}, \mathrm{Mn})_{3} \mathrm{C}\right]$, raises some questions and merits further discussion. This fraction is $5 \%$ based on the CXMS resonance and it is $30 \%$ based on that of the CEMS. The 5\% CXMS fraction seems reasonable assuming the $\mathrm{CrFe}$-carbide phase, $\mathrm{Cr}_{\sim 16} \mathrm{Fe}_{\sim 7} \mathrm{C}_{6}$, has converted into cementite $\left(\mathrm{Fe}_{3} \mathrm{C}\right)$ and that all the carbon from the carbide is used to form the cementite (the $2 \%$ CXMS resonance signal in the as-polished state should increase to about $5 \%$ in the $\mathrm{N}_{2} /$ $\mathrm{H}_{2}=1 / 10$ sample). On the other hand, the much larger CEMS resonance fraction (30\%) seems difficult to explain unless there is some carbon segregation taking place in the surface region $(\sim 0.1 \mu \mathrm{m})$. We believe that the larger fraction is due to the extra carbon in the nitriding chamber because plastic injection mould materials to be nitrided along with our specimens probably were not cleaned carefully and had some oil residues on them before the nitriding step. The extra carbon may also be entering the nitriding system via the diffusion pump. Note that the CEMS and CXMS cementitelike resonance fractions for the $\mathrm{N}_{2} / \mathrm{H}_{2}=1 / 1$ sample are about the same $(\sim 23 \%)$, and the $23 \%$ CXMS fraction may be interpreted as the conversion of the $\mathrm{CrFe}$-carbide phase into the cementite-like phase deeper in the substrate assuming the extra $\mathrm{C}$ is supplied by the mechanism(s) just mentioned.

In addition, the clear observation of $\gamma^{\prime}-\mathrm{Fe}_{4} \mathrm{~N}$ nitride by XRD for the specimens nitrided under the $\mathrm{N}_{2} / \mathrm{H}_{2}=1 / 1$ and $3 / 1$ nitriding conditions (Fig. 1), but not by CEMS, can be explained by the fact that the presence of a small amount of $\gamma^{\prime}$ nitride resonance may be masked by the $\varepsilon$-nitride, $\mathrm{Fe}_{3} \mathrm{C}$-like carbide, and $\alpha-\mathrm{Fe}(\mathrm{Mn})$ signals. The Mössbauer parameters associated with $\gamma^{\prime}-\mathrm{Fe}_{4} \mathrm{~N}$ phase can be found in Ref. [11].

\section{SEM results and discussion}

Cross-sectional SEM analysis was done on the specimens S10, S3, and S14 with the corresponding gas flow 
ratios of $\mathrm{N}_{2} / \mathrm{H}_{2}=1 / 10,1 / 1$, and $3 / 1$, and the results are shown in Fig. 4. The $\mathrm{N}_{2} / \mathrm{H}_{2}=1 / 10$ sample SEM pictures (the top photomicrographs in Fig. 4) clearly reveal the nitrided layer with a relatively uniform layer thickness. However, the chemical etch used (nital) strongly attacks the nitrided layer region, which is identified as phase-separated $\mathrm{CrN}+\alpha-$ $\mathrm{Fe}(\mathrm{Mn})$ based on the XRD/CEMS/CXMS results. The chemical etch also reveals the grain structure of the underlying substrate phase due to the longer etching times used ( $15 \mathrm{~s})$. The top (on the right) photomicrograph with a higher magnification of the same region as in the top left picture taken along the nitrided layer clearly reveals the microstructure of the nitrided layer under the 1/10 conditions. This picture, when examined carefully, shows that the nitrided layer is composed of fine precipitates of $\mathrm{CrN}$. The nitrided layer thickness is estimated from several pictures taken along the nitrided layer. Careful analysis reveals the nitrided layer microstructures with thicknesses as low as $17 \mu \mathrm{m}$ and as high as $20 \mu \mathrm{m}$.

Fig. 4 also shows the SEM results for the specimen plasma ion nitrided under the $\mathrm{N}_{2} / \mathrm{H}_{2}=1 / 1$ gas flow ratio. The middle (on the left) photomicrograph is composed of two
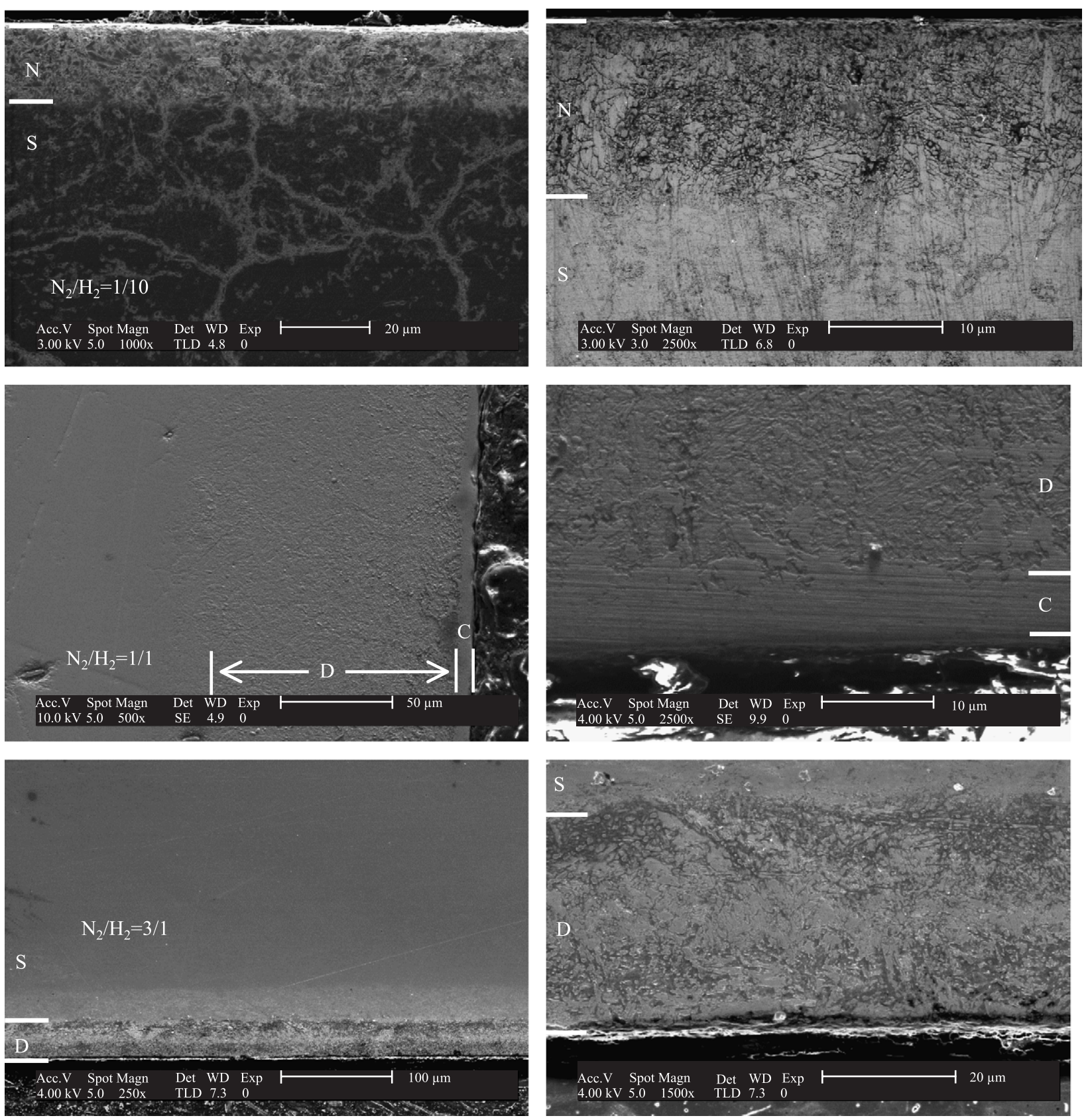

Fig. 4. SEM data for the specimens plasma nitrided under the $\mathrm{N}_{2} / \mathrm{H}_{2}=1 / 10,1 / 1$, and $3 / 1$ plasma conditions. The photomicrographs on the right-hand side refer to the same region as in the photomicrographs on the left-hand side but with higher magnification. In these photomicrographs, "S" refers to the substrate, "N" to the nitrided layer, "C" to the compound layer, and "D" to the diffusion layer. 
Table 3

Salt spray corrosion analysis results

\begin{tabular}{lc}
\hline Nitriding gas composition $\left(\mathrm{N}_{2} / \mathrm{H}_{2}\right)$ & Corrosion initiation duration $(\mathrm{h})$ \\
\hline As-polished specimen & 3 \\
$1 / 10$ & 2 \\
$1 / 1$ & $>8^{\mathrm{a}}$ \\
$3 / 1$ & 2 \\
\hline
\end{tabular}

${ }^{a}$ This experiment had to be stopped without observing corrosion initiation in $8 \mathrm{~h}$.

distinct regions, one of which (the compound layer) has a thickness ranging from 7 to $12 \mu \mathrm{m}$ with a good etch resistance, and the other (the diffusion layer) with a thickness ranging from 120 to $130 \mu \mathrm{m}$ and with a relatively poor etch resistance. The compound layer consists of the $\varepsilon$ nitride, $\gamma^{\prime}$-nitride, the cementite-like phase, and $\mathrm{CrN}$ based on the XRD/CEMS/CXMS results for this sample, while the diffusion layer contains fine precipitates of $\mathrm{CrN}$ based on the SEM results (the middle photomicrograph on the right in Fig. 4 clearly reveals the precipitation region of the diffusion layer). As can be clearly seen from the middle photomicrographs in Fig. 4, the compound layer is not attacked by the chemical etch used (nital), indicating high etch resistance for the $\mathrm{N}_{2} / \mathrm{H}_{2}=1 / 1$ conditions. The average total nitrided layer thickness for the $\mathrm{N}_{2} / \mathrm{H}_{2}=1 / 1$ conditions (compound layer+diffusion layer thicknesses) estimated based on several photomicrographs is found to be $\sim 135 \mu \mathrm{m}$.

The bottom SEM photomicrographs (Fig. 4) for the specimen plasma nitrided under the $\mathrm{N}_{2} / \mathrm{H}_{2}=3 / 1$ conditions also show the uniform nature of the nitrided layer. The bottom left picture reveals two distinct regions, one of which has a thickness of $\sim 40 \mu \mathrm{m}$ and is strongly attacked by the chemical etch used, while the other with a thickness of $\sim 30 \mu \mathrm{m}$ has a slightly better etch resistance. The photomicrograph of the near-surface region (with $\sim 40-\mu \mathrm{m}$-thick layer) with higher magnification (the bottom right picture) clearly reveals the precipitate microstructure nature of the top nitrided layer $(\sim 40 \mu \mathrm{m})$. Although the XRD and CEMS/ CXMS showed the presence of $\varepsilon$ - and $\gamma^{\prime}$-nitride in this $\mathrm{N}_{2} /$ $\mathrm{H}_{2}=3 / 1$ specimen, they apparently do not result in a welldefined compound layer according to SEM results.

\section{Corrosion analysis results}

In addition to chemical etching during SEM sample preparation, the corrosion behaviour of the nitrided specimens was investigated by a salt spray method (ASTM B $117 ; 2 \% \mathrm{NaCl}$ solution in distilled water). The salt spray analysis involved in subjecting the as-polished and plasmanitrided specimens to a dispersed mist, consisting of $2 \%$ salt solution in distilled water. During the analysis, the specimens are regularly checked by visual means whether any corrosion initiation (when the corrosion products start covering the surface) occurs or not. More details regarding the salt spray corrosion test(s) can be found in Ref. [12].
After the tests, the surface morphologies were inspected via optical microscope. The results are shown in Table 3. As can be seen from this table, an excellent improvement in corrosion resistance is observed for the specimen nitrided under the $\mathrm{N}_{2} / \mathrm{H}_{2}=1 / 1$ gas flow ratio. While the time for corrosion initiation for the substrate material is $3 \mathrm{~h}$, it lasts much longer (more than two and a half times) for the $\mathrm{N}_{2} /$ $\mathrm{H}_{2}=1 / 1$ nitrided layer. The corrosion initiation for the specimens nitrided under the $\mathrm{N}_{2} / \mathrm{H}_{2}=1 / 10$ and $3 / 1$ gas mixture ratios takes place at about the same time, namely $2 \mathrm{~h}$. This indicates that these specimens have poorer corrosion resistances in comparison to that of the substrate material. The reason for the poor corrosion behaviour for these samples can be attributed to the formation of chromium nitride based on the XRD results for these samples. The poor corrosion results also agree quite well with the etching results for the same specimens.

The best corrosion behaviour is thus obtained for the specimen nitrided under the $\mathrm{N}_{2} / \mathrm{H}_{2}=1 / 1$ gas flow ratio conditions although the XRD results for this specimen finds $\mathrm{CrN}$ to be one of the phases existing in the top nitrided layers (the compound layer). The enhanced corrosion resistance is attributed to the formation of a well-defined compound layer (see the photomicrographs in Fig. 4). Note that the XRD/CEMS/CXMS results for this sample show that the top nitrided layer is rich in $\varepsilon$-nitride. These results also agree quite well with the plasma nitriding study mentioned earlier (Ref. [4]) which showed that the nitrided layer with the $\varepsilon$-phase has an excellent corrosion resistance.

\section{Cross-sectional nanohardness results and discussion}

The nanohardness depth profiling measurements of the plasma ion nitrided specimens are shown in Fig. 5. The results clearly show that the hardness of the nitrided specimens is increased by about a factor of three in comparison to that of the substrate material. The most

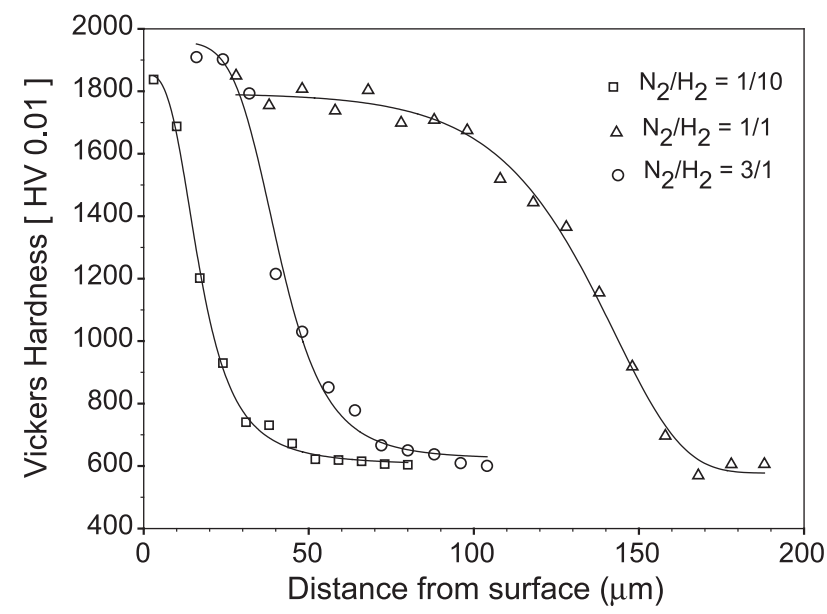

Fig. 5. The cross-sectional hardness-depth distributions for the nitrided specimens. 
important characteristic of the hardness-depth profiles is that they show plateau-shaped behaviour, in particular, for the $\mathrm{N}_{2} / \mathrm{H}_{2}=1 / 1$ nitriding conditions. This distinct characteristic is normally associated with the hardness profiles of high-chromium steels and is attributed to the strong interaction nature of the $\mathrm{Cr}$ [6]. From the hardness-depth profiles, the hardness-depth (defined as the depth at which the hardness has decreased to half its near surface value) is estimated to be 25,50 , and $150 \mu \mathrm{m}$ for the $\mathrm{N}_{2} / \mathrm{H}_{2}=1 / 10-, 3$ / 1-, and 1/1-nitrided specimens, respectively. These depths correlate well with the nitrided layer thicknesses obtained by the cross-sectional SEM analyses results.

The increase in hardness across the nitrided layer is attributed in part to the presence of fine precipitates of $\mathrm{CrN}$. The high affinity of chromium for nitrogen drives the formation of homogeneously dispersed fine $\mathrm{CrN}$ precipitates, increasing the hardness of the nitrided layer via the dispersion-hardening mechanism. In addition, compressive stresses in the nitrided layer might contribute to the hardening effect because the presence of alloy nitrides (i.e., $\varepsilon$-nitride and $\mathrm{CrN}$ ) in the iron matrix causes some structural misfit resulting in compressive stresses in the layer [8].

\section{Conclusions}

The effect of varying nitriding gas composition $\left(\mathrm{N}_{2}+\mathrm{H}_{2}\right)$ on the microstructural, mechanical and corrosion characteristics of plasma nitrided X36CrMo17 ferritic stainless steel used for injection moulding was investigated. The experimental SEM results show that the nitrided layer thickness is maximized near the $\mathrm{N}_{2} / \mathrm{H}_{2}=1 / 1$ plasma nitriding conditions and this correlates well with an excellent corrosion behaviour and plateau-shaped hardness profile found from corrosion tests and cross-sectional nanohardness measurements. Combined XRD and Mössbauer analyses indicate that the $\varepsilon$-nitride, $\gamma^{\prime}$-nitride, $\mathrm{CrN}$, and the cementite-like phases are distributed in the top nitrided layers of several micron thickness. The CEMS and CXMS analyses show the nearly complete decomposition of these layers into pure $\alpha$ $\mathrm{Fe}, \varepsilon$-nitride, cementite-like carbide, and $\mathrm{CrN}$. The SEM photomicrographs quite clearly reveal the uniform and fine precipitate microstructure $(\mathrm{CrN})$ nature of the nitrided layers, composed of compound and diffusion layers, several microns in thickness. The excellent etch resistance and corrosion behaviour of the nitrided layer is attributed to the compound layer $\varepsilon$-nitride phase. The cross-sectional nanohardness measurements show that the surface layer hardness under all nitriding conditions is increased by about a factor of 3 in comparison to that of the substrate. The enhanced hardness is attributed to the fine precipitates of $\mathrm{CrN}$ distributed within the nitrided layer together with likely compressive stresses. The appearance and enhancement of the $(\mathrm{Fe}, \mathrm{Cr}, \mathrm{Mn})_{3} \mathrm{C}$-cementite-like phase in the near-surface region and as well as much deeper into the substrate is attributed to the conversion of the substrate carbide phase $\left(\mathrm{Cr}_{\sim 16} \mathrm{Fe}_{\sim 7} \mathrm{C}_{6}\right)$, together with carbon segregation to the nearsurface region and some extra carbon being present in the nitriding system.

\section{Acknowledgments}

The study presented here satisfies one of the aims of a larger research and development project (Tubitak-Tidep \#3000249) directed by Prof. A. Öztarhan who is presently affiliated with Tubitak Textile Research Center, Ege University, Izmir, Turkey. The authors would also like to thank Besok Kalipcilik and Donmez Debriyaj for providing the materials for this study and salt spray corrosion analysis, respectively.

\section{References}

[1] Christen A. Straede, Nucl. Instrum. Methods, B 113 (1996) 161.

[2] N.J. Mikkelsen, J. Pedersen, C.A. Straede, Surf. Coat. Technol. 158-159 (2002) 42.

[3] M. Berg, C.V. Budtz-Jorgensen, H. Reitz, Surf. Coat. Technol. 124 (2000) 25.

[4] T. Michler, M. Grischke, K. Bewilogua, H. Dimigen, Thin Solid Films 322 (1998) 206.

[5] B. Larisch, U. Brusky, H.-J. Spies, Surf. Coat. Technol. 116-119 (1999) 205

[6] C.E. Pinedo, W.A. Monteiro, J. Mater. Sci. Lett. 20 (2001) 147.

[7] D.L. Williamson, F.M. Kustas, D.F. Fobare, M.S. Misra, J. Appl. Phys. 80 (1986) 1493.

[8] N.L. Loh, L.W. Siew, Surf. Eng. 15 (1999) 137.

[9] K.E. Eickel, W. Pitch, Phys. Status Solidi 39 (1970) 121.

[10] G.M. Chen, N.K. Jaggl, J.B. Butt, E.B. Yeh, L.H. Schwartz, J. Phys. Chem. 87 (1983) 5326.

[11] Peter Schaaf, Christof Illgner, M. Niederdrenk, K.P. Lieb, Hyperfine Interact. 95 (1995) 199.

[12] Web site for American Society for Testing and Materials (ASTM), http://www.astm.org. 